\title{
NUMERICAL MODELLING OF THE SOIL BEHAVIOUR BY USING NEWLY DEVELOPED ADVANCED MATERIAL MODEL
}

\author{
JAN VESELY
}

\begin{abstract}
Department of Geotechnics, Faculty of Civil Engineering, Czech Technical University in Prague, Thakurova 7 , Prague, Czech Republic

correspondence: veselyjan@centrum.cz
\end{abstract}

\begin{abstract}
This paper describes a theoretical background, implementation and validation of the newly developed Jardine plastic hardening-softening model (JPHS model), which can be used for numerical modelling of the soils behaviour. Although the JPHS model is based on the elasto-plastic theory, like the Mohr-Coulomb model that is widely used in geotechnics, it contains some improvements, which removes the main disadvantages of the MC model. The presented model is coupled with an isotopically hardening and softening law, non-linear elastic stress-strain law, non-associated elasto-plastic material description and a cap yield surface. The validation of the model is done by comparing the numerical results with real measured data from the laboratory tests and by testing of the model on the real project of the tunnel excavation. The 3D numerical analysis is performed and the comparison between the JPHS, Mohr-Coulomb, Modified Cam-Clay, Hardening small strain model and monitoring in-situ data is done.
\end{abstract}

KEYWORDS: numerical modelling; advanced material model; soils; small strain stiffness; tunnel excavation.

\section{INTRODUCTION}

In the last few years, the numerical analyses are increasingly used in the design of the underground structures 1 ] 8 . The designers can work with different userfriendly commercial software and relatively easy simulate the behaviour of the soil mass. Unfortunately, one important fact is overlooked. Numerical analyses are only approximation of real behaviour and are highly dependent on the input parameters [9, 10]. One area, which can affect the calculated results, is the correct choice of the material model [11-13]. Many laboratory tests show that the behaviour of soils is highly nonlinear [14 16] and therefore the use of a common linear elasto - perfectly plastic material models based on the Mohr-Coulomb yield criterion is not appropriate. Instead, the advanced material model like a newly developed Jardine plastic hardening-softening model (the JPHS model) should be used.

\section{TheOreticAl BACKGROUND OF THE MODEL}

The Jardine plastic hardening-softening model (the JPHS model) is based on the elasto - plastic theory as in geotechnics widely used Mohr-Coulomb model, but it contains some other features, which improve its capabilities and allow better simulations of the ground behaviour. Firstly, the Mohr-Coulomb failure yield criterion is replaced by the Willam-Warnke failure yield criterion, which eliminates the singular tips from the Mohr-Coulomb surface and has a better agreement with the data from the experimental tests. Secondly, the model contains non-associated material description and the plastic flow is controlled by the Drucker-Prager potential function. Thirdly, the model has the ability to simulate the non-linear isotropic hardening and softening of the soils. Fourthly, it is capable to increase the stiffness modulus with an increasing depth or stress level. Fifthly, the volumetric hardening is controlled by a cap yield surface and finally, the model has the possibility to calculate the non-linear stress-strain dependence in a small strain range.

\subsection{Yield FAILURE CRITERION}

The Mohr-Coulomb failure criterion for soils is one of the oldest failure criteria. It is experimentally verified in triaxial compression and extension, but it is also very conservative for intermediate principal stress states between the triaxial compression and extension as can be seen in Figure 1 To eliminate this conservative behaviour and approximate the JPHS model more to the reality, the Willam-Warnke failure criterion [17] is implemented in the model. If $r_{\mathrm{c}}$ is the distance from the hydrostatic axis to the failure surface at the compressive meridian and $r_{\mathrm{t}}$ at the tension meridian, then at any intermediate position, the distance $r$ is given by (see Figure 2):

$$
r=\frac{2 r_{\mathrm{c}}\left(r_{\mathrm{c}}^{2}-r_{\mathrm{t}}^{2}\right) \cos \theta+r_{\mathrm{c}}\left(2 r_{\mathrm{t}}-r_{\mathrm{c}}\right) \sqrt{D_{1}}}{4\left(r_{\mathrm{c}}^{2}-r_{\mathrm{t}}^{2}\right) \cos ^{2} \theta+\left(r_{\mathrm{c}}-2 r_{\mathrm{t}}\right)^{2}},
$$

where

$$
D_{1}=4\left(r_{\mathrm{c}}^{2}-r_{\mathrm{t}}^{2}\right) \cos ^{2} \theta+5 r_{\mathrm{t}}^{2}-4 r_{\mathrm{t}} r_{\mathrm{c}} .
$$




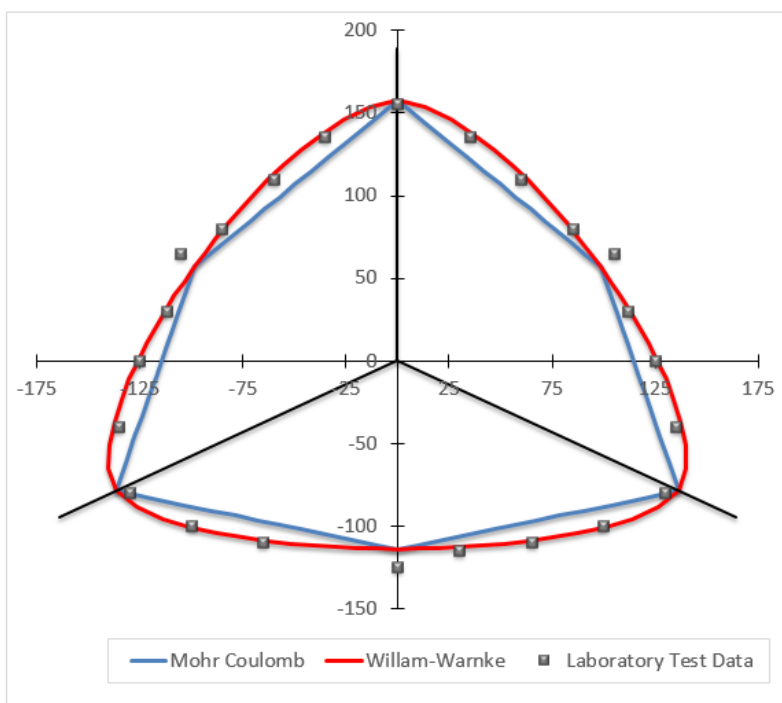

Figure 1. The three-dimensional failure surface of Kaolin Clay in octahedral plane, lab. data from [18.

After several mathematical operations, the locus of yield surface in deviatoric plane can be written as:

$$
g(\theta)=\frac{2\left(1-e^{2}\right) \cos \theta+(2 e-1) \sqrt{D_{2}}}{4\left(1-e^{2}\right) \cos ^{2} \theta+(2 e-1)^{2}},
$$

where

$$
\begin{gathered}
D_{2}=4\left(1-e^{2}\right) \cos ^{2} \theta+5 e^{2}-4 e, \\
e=\frac{r_{\mathrm{c}}}{r_{\mathrm{t}}}=\frac{3-\sin \phi^{\prime}}{3+\sin \phi^{\prime}} .
\end{gathered}
$$

And the whole Willam-Warnke failure criterion can be expressed as follows:

$$
F=A_{1} p+\frac{q}{g(\theta)}+A_{2}=0
$$

where

$$
A_{1}=-\frac{6-\sin \phi^{\prime}}{3-\sin \phi^{\prime}}, \quad A_{2}=-\frac{6 c-\sin \phi^{\prime}}{3-\sin \phi^{\prime}} .
$$

On the one hand, it is evident that the formula is relatively complex which can cause some difficulties during evaluation of differential and secondary order differential form, but on the other hand, this complexity allows that the locus of yield surface in deviatoric plane has the following features:

- fits with the Mohr-Coulomb key points; i.e., the experimental extension and compression meridian points are on the curve;

- it is differentiable at the compression and extension meridian points; i.e., the singularities in the corner, which cause the numerical difficulties, are eliminated;

- it is convex in the whole range of $0<\phi \leq \pi / 2$ $(0.5<e \leq 1)$.

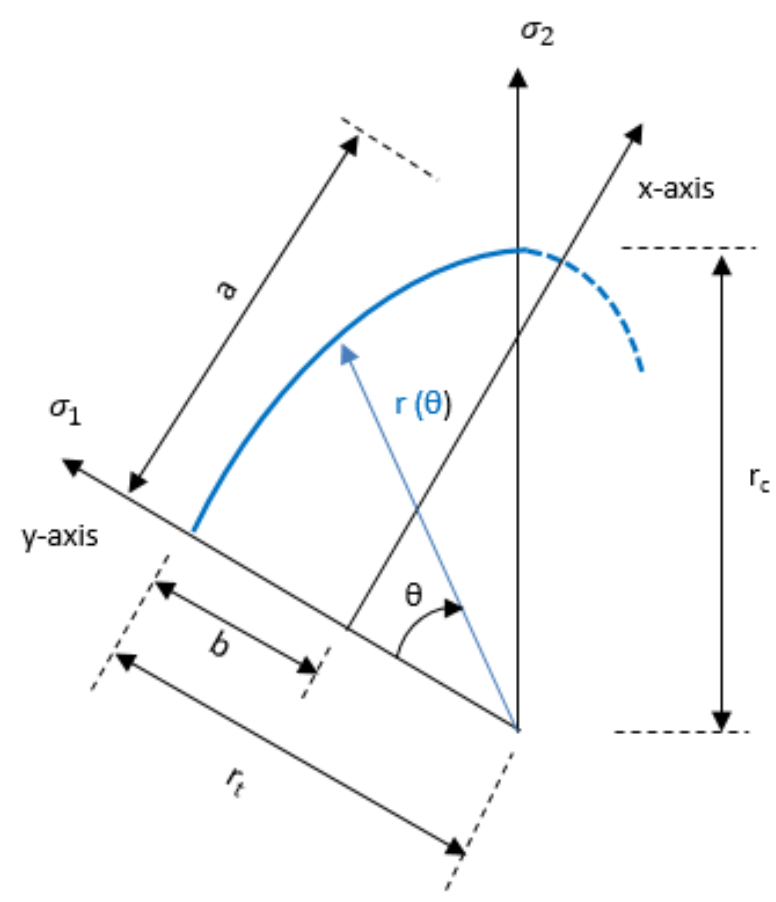

Figure 2. The geometrical interpretation of WillamWarnke failure criteria.

\subsection{Plastic FLOW}

The JPHS model contains the non-associated material description and the plastic flow is controlled by the Drucker-Prager yield criterion [19] that has the following form:

$$
F=\sqrt{J_{2}}-\alpha_{\mathrm{DP}} I_{1}-k=0
$$

The coefficients $\alpha_{\mathrm{DP}}$ and $k_{\mathrm{DP}}$ are not commonly used parameters in geotechnics and a proper calibration can lead to some difficulties in practice. Since the Drucker-Prager yield surface is a smooth version of the Mohr-Coulomb yield function, the Drucker-Prager constants can be expressed in terms of cohesion and friction angle. By relating hydrostatic stress $\mathrm{p}$ and deviatoric stress q to the invariants $I_{1}$ and $J_{2}$ the form of Drucker-Prager yield criterion can be rewritten as follows :

$$
\begin{gathered}
F=\frac{q}{\sqrt{3}}-3 p \alpha_{\mathrm{DP}}-k=0, \\
\rightarrow F=-3 \sqrt{3} p \alpha_{\mathrm{DP}}+q-\sqrt{3} k=0,
\end{gathered}
$$

where the coefficient $\alpha_{\mathrm{DP}}$ and $k_{\mathrm{DP}}$ can be expressed for the triaxial compression and extension:

$$
\begin{aligned}
\alpha_{\mathrm{CTC}} & =\frac{2 \sin \psi}{\sqrt{3}(3-\sin \psi}, \alpha_{\mathrm{CTE}}=\frac{2 \sin \psi}{\sqrt{3}(3+\sin \psi}, \\
k_{\mathrm{CTC}} & =\frac{6 c \sin \psi}{\sqrt{3}(3-\sin \psi}, k_{\mathrm{CTE}}=\frac{6 c \sin \psi}{\sqrt{3}(3+\sin \psi} .
\end{aligned}
$$

And the general form of the Drucker-Prager potential function is then:

$$
F=A_{1} p+\frac{q}{g(\theta)}+A_{2}=0
$$




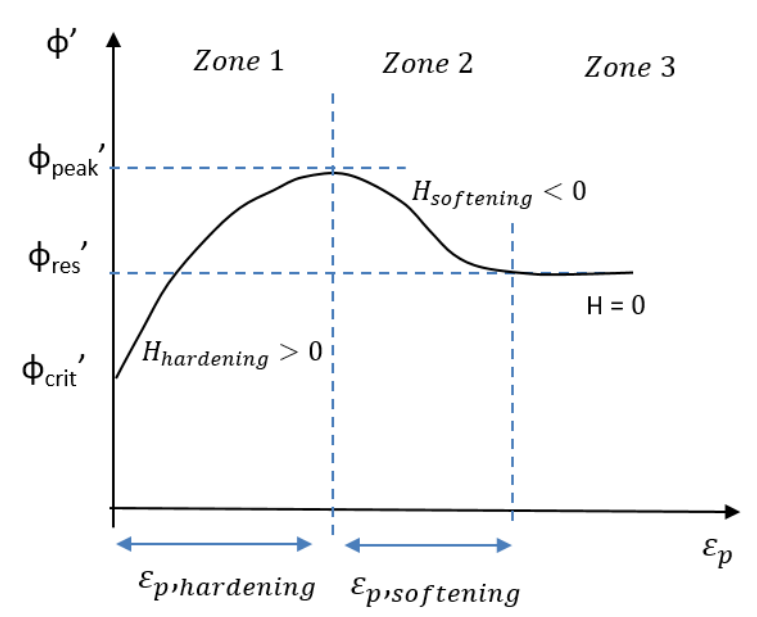

Figure 3. The hardening-softening law - dependence of friction angle on equivalent deviatoric plastic deformation.

where

$$
A_{1}=-\frac{6-\sin \psi}{3-\sin \psi}, A_{2}=-\frac{6 c-\sin \psi}{3-\sin \psi}, g(\theta)=1 .
$$

\subsection{NON-LINEAR HARDENING/SOFTENING}

In the JPHS model, the isotropic hardening rule is used to describe the hardening and softening law. The change in yield criterion can be described as follows:

$$
d F=\frac{\partial F}{\partial \sigma_{i j}} \mathrm{~d} \sigma_{i j}+h\left(\mathrm{~d} \epsilon^{\mathrm{p}}\right) .
$$

According to the strain hardening hypothesis [20, hardening process can be work hardening or strain hardening. To cover both cases, it is useful to define the hardening variable $\mathrm{d} \kappa$ and the parameter $\mathrm{H}$, which express the $\mathrm{d} \kappa$ in terms of equivalent plastic strain $\mathrm{d} \epsilon^{\mathrm{p}}$ :

$$
H=\frac{\mathrm{d} \kappa}{\mathrm{d} \epsilon^{\mathrm{P}}} .
$$

The change in the yield function can then be rewritten as follows:

$$
\begin{gathered}
d F=\frac{\partial F}{\partial \sigma_{i j}} \mathrm{~d} \sigma_{i j}+\frac{\partial F}{\partial \kappa} \mathrm{d} \kappa=0 \\
\rightarrow d F=\frac{\partial F}{\partial \sigma_{i j}} \mathrm{~d} \sigma_{i j}+\frac{\partial F}{\partial \kappa} \frac{\mathrm{d} \kappa}{\mathrm{d} \epsilon^{\mathrm{p}}} \frac{\mathrm{d} \epsilon^{\mathrm{p}}}{\mathrm{d} \lambda} \mathrm{d} \lambda=0,
\end{gathered}
$$

where the equivalent plastic strain can also be characterised as follows:

$$
\mathrm{d} \epsilon^{\mathrm{p}}=\sqrt{\frac{2}{3} \mathrm{~d} \epsilon^{\mathrm{p}}: \mathrm{d} \epsilon^{\mathrm{p}}}=\sqrt{\frac{2}{3}} \mathrm{~d} \lambda \sqrt{\mathrm{d} Q} .
$$

Finally, substituting equations (16), (17) and (19) gives the expression of the hardening function $h_{\kappa}$, which is directly related to the input parameter $\mathrm{H}$ :

$$
h_{\kappa}=\sqrt{\frac{2}{3}} H \sqrt{\mathrm{d} Q} \frac{\partial F}{\partial \kappa} .
$$

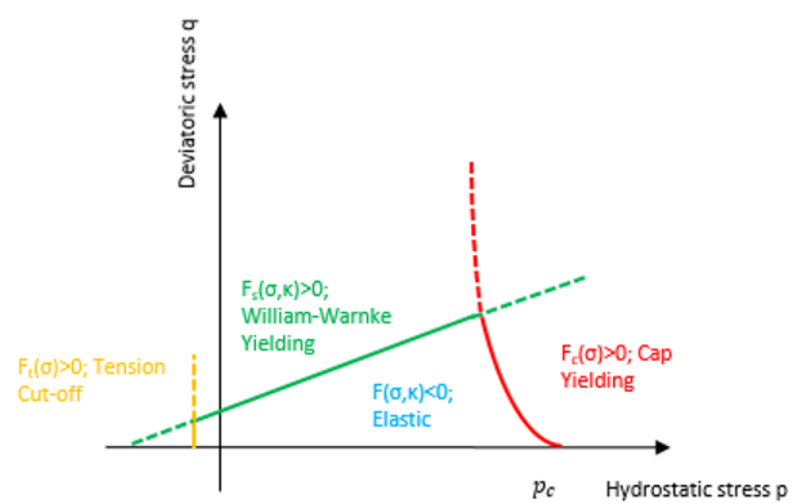

Figure 4. Cap yield surface in p-q plane.

The JPHS model allows to assume the variation of friction angle $\phi^{\prime}$ with accumulated plastic strain as shown in Figure 3. There are three zones. In zone 1, $\phi^{\prime}$ is assumed to increase from the initial value $\left(\phi_{\text {crit }}^{\prime}\right)$ to the peak value $\left(\phi_{\text {peak }}^{\prime}\right)$ while in zone $2, \phi^{\prime}$ is reduced from the peak value to the residual value $\left(\phi_{\text {res }}^{\prime}\right)$ and in zone $3, \phi^{\prime}$ remains constant and equal to the residual value $\left(\phi_{\text {res }}^{\prime}\right)$. In each of these zones, mathematical expressions can be assigned to the variation of $\phi^{\prime}$ with equivalent plastic strain $\mathrm{d} \epsilon^{\mathrm{p}}$, and therefore the hardening/softening rules can be expressed in a piecewise manner and the parameter $\mathrm{H}$ is defined in the JPHS model as follows:

$$
\begin{aligned}
H_{\text {hardening }} & =\frac{\left(\phi_{\text {peak }}^{\prime}-\phi^{\prime}\right)^{\delta}}{\epsilon_{\text {hardening }}}, \\
H_{\text {softening }} & =\frac{\left(\phi^{\prime}-\phi_{\mathrm{res}}^{\prime}\right)^{\delta}}{\epsilon_{\text {softening }}} .
\end{aligned}
$$

Note that $\phi_{\text {peak }}^{\prime}, \phi_{\text {res }}^{\prime}, \delta, \epsilon_{\text {hardening }}, \epsilon_{\text {softening }}$ are input parameters, which are based on the result of the triaxial tests

\subsection{CAP YIELD SURFACE}

The shear yield surface defined in $\$ 2.1$ does not explain the plastic volume strain that is measured in the isotropic compression. Therefore, the second type of yield surface is implemented in the JPHS model to close the elastic region for compressive stress path. The shape of cap yield surface in p-q plane (see Figure 4) is chosen in the way to get the best agreement with the laboratory test data and is defined as follows:

$$
F=p+k_{\text {cap }}-\frac{q_{\mathrm{c}}-q}{q_{\mathrm{c}}}-p_{\mathrm{c}}=0 .
$$

The initial pre-consolidation is calculated according to the following equation:

$$
\begin{gathered}
p_{c, \text { ini }}=\operatorname{OCR}\left(p_{\text {ini }}+k_{\text {cap }} q_{\text {ini }}\right), \\
q_{c, \text { ini }}=\frac{6 \sin \phi_{\text {peak }}^{\prime}}{3-\sin \phi_{\text {peak }}^{\prime}} p_{c, i n i}+\frac{6 c \sin \phi_{\text {peak }}^{\prime}}{3-\sin \phi_{\text {peak }}^{\prime}} .
\end{gathered}
$$

During the volumetric strain hardening, the value of pre-consolidation pressure is then updated as follows:

$$
p_{\mathrm{c}}=p_{\mathrm{c}, \text { ini }}+K \epsilon_{\mathrm{v}} .
$$




\subsection{NON-LINEAR ELASTICITY}

The strain range, in which the soils can be considered truly elastic, is very small and with increasing strain amplitude, soil stiffness decays non-linearly. To simulate this soil behaviour, non-linear elastic stress-strain law, based on the Jardine function, is implemented in the model.

Jardine et al. [14 proposed a periodic logarithmic function to express the non-linear relationship between the normalized secant Young's modulus $E_{\mathrm{u}}$ and axial strain $\epsilon_{\mathrm{a}}$ as follows:

$$
\frac{E_{\mathrm{u}}}{c_{\mathrm{u}}}=A+B \cos \left(\alpha \log \left(\frac{\epsilon_{\mathrm{a}}}{C}\right)^{\gamma}\right),
$$

where $A, B, C, \alpha, \gamma$ are the Jardine material model constants based on triaxial tests.

The normalized tangent Young's modulus $E_{\mathrm{ut}}$ corresponding to the secant Young's modulus $E_{\mathrm{u}}$ can be derived by a differentiating and rearranging (27):

$$
\begin{aligned}
\frac{E_{\mathrm{ut}}}{c_{\mathrm{u}}}=A+B \cos \left(\alpha \log \left(\frac{\epsilon_{\mathrm{a}}}{C}\right)^{\gamma}\right) & \\
& -\frac{B \alpha \gamma \log \left(\frac{\epsilon_{\mathrm{a}}}{C}\right)^{\gamma-1}}{2.303} .
\end{aligned}
$$

For the purpose of the numerical modelling, it is appropriate to replace the axial strain $\epsilon_{\mathrm{a}}$ by deviatoric strain invariant $\epsilon_{\mathrm{dev}}$ that is defined as:

$$
\epsilon_{\mathrm{dev}}=\sqrt{\frac{2}{3}\left(\left(\epsilon_{1}-\epsilon_{2}\right)^{2}+\left(\epsilon_{2}-\epsilon_{3}\right)^{2}+\left(\epsilon_{3}-\epsilon_{1}\right)^{2}\right)} .
$$

By substituting the stress state of the undrained triaxial test $\left(\epsilon_{1}=\epsilon_{\mathrm{a}}\right.$ and $\left.\epsilon_{2}=\epsilon_{3}=-\frac{1}{1} \epsilon_{\mathrm{a}}\right)$ into the equation (29), the dependence between axial strain $\epsilon_{\mathrm{a}}$ and deviatoric strain invariant is $\epsilon_{\mathrm{dev}}=\sqrt{3} \epsilon_{\mathrm{a}}$ and the normalized tangent Young's modulus $E_{\text {ut }}$ can be rewritten as follows:

$$
\begin{aligned}
& \frac{E_{\mathrm{ut}}}{c_{\mathrm{u}}}=A+B \cos \left(\alpha \log \left(\frac{\epsilon_{\mathrm{dev}}}{\sqrt{3} C}\right)^{\gamma}\right) \\
&-\frac{B \alpha \gamma \log \left(\frac{\epsilon_{\mathrm{dev}}}{\sqrt{3} C}\right)^{\gamma-1}}{2.303} .
\end{aligned}
$$

Finally, to simulate the dependency of the modulus with the depth or stress level, the equation is modified as follows [21]:

$$
E_{\mathrm{ut}}=\sigma_{\mathrm{m}}\left(A+B \cos \left(\alpha I^{\gamma}\right)-\frac{B \alpha \gamma I^{\gamma-1}}{2.303} \sin \left(\alpha I^{\gamma}\right)\right),
$$

where $\sigma_{\mathrm{m}}$ is mean stress pressure and $I=\log \frac{\epsilon_{\mathrm{dev}}}{\sqrt{3} C}$.

Due to the Jardine model's trigonometric nature, it is also mandatory to specify the exact strain range, in which the non-linear stress-strain law is to be applied. When exceeding the upper $\left(\epsilon_{\max }\right)$ or lower $\left(\epsilon_{\min }\right)$ limit of the strain range specified, stiffness is set as constant. A practical value for $\epsilon_{\min }$ is the smallest strain for which the test data is available. For $\epsilon_{\max }$ it is required to ensure compatibility with onset of plastic yield and check that high value will not gain to the negative tangent Young's modulus (see Figure 5).

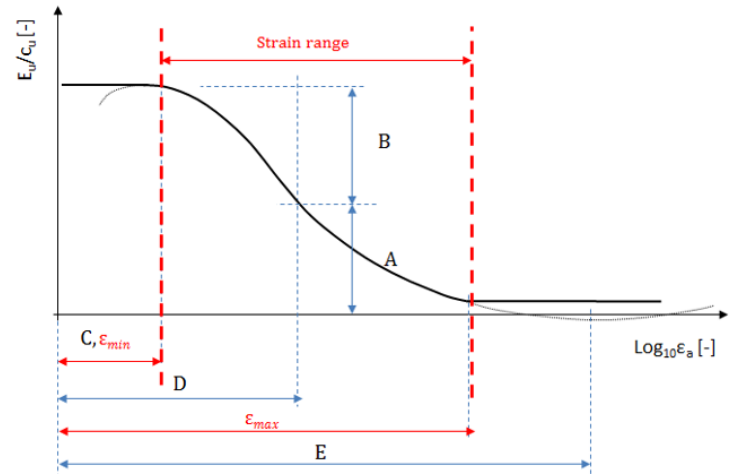

FiguRE 5. Jardine function — strain range.

\section{IMPLEMENTATION OF THE MODEL}

The software PLAXIS allows users to implement a wide range of material models into the program. These models must be programmed in FORTRAN language, compiled as a Dynamic Link Library (DLL), and then added to the PLAXIS program directory. These models simulate the soil behaviour in a single material point and the global behaviour is then governed by the Finite Element Method implementation in PLAXIS.

The whole flow chart containing all steps needed for implementation of the model is presented in Figure 7. The first action that must be done is the declaration and initialization of the material properties and state variables and the specification of the undrained behaviour.

The second action is to calculate the current value of the E-modulus. This is done by calling the following three subroutines:

STRAIN_CALCULATION: This subroutine is calculating the deviatoric strain invariant $\epsilon_{\mathrm{dev}}$ according to the formula 29 . The input parameters are all components of the total strains and the output is the deviatoric strain invariant $\epsilon_{\mathrm{dev}}$.

JARDINE: This subroutine is calculating the current E-modulus according to the formula (31) and rules mentioned in Section 2.5. The input parameters are the deviatoric strain invariant $\epsilon_{\mathrm{dev}}$ and the JPHS model parameters. The output is the actual E-modulus

UNLOADING: This subroutine is controlling the value of the E-modulus during unloading and reloading cycles according to the formula:

$$
E_{\text {unload }}=E k_{\text {unload }},
$$

where $k_{\text {unload }}$ is an unloading coefficient

The fourth action is the calculation of the actual hardening / softening parameter by using the user defined subroutine HARDENING. The input of this subroutine is the JPHS model parameters. The output is a new value of the Hardening / Softening parameter $H$, determined according to the formulas (21) and $(22)$. 


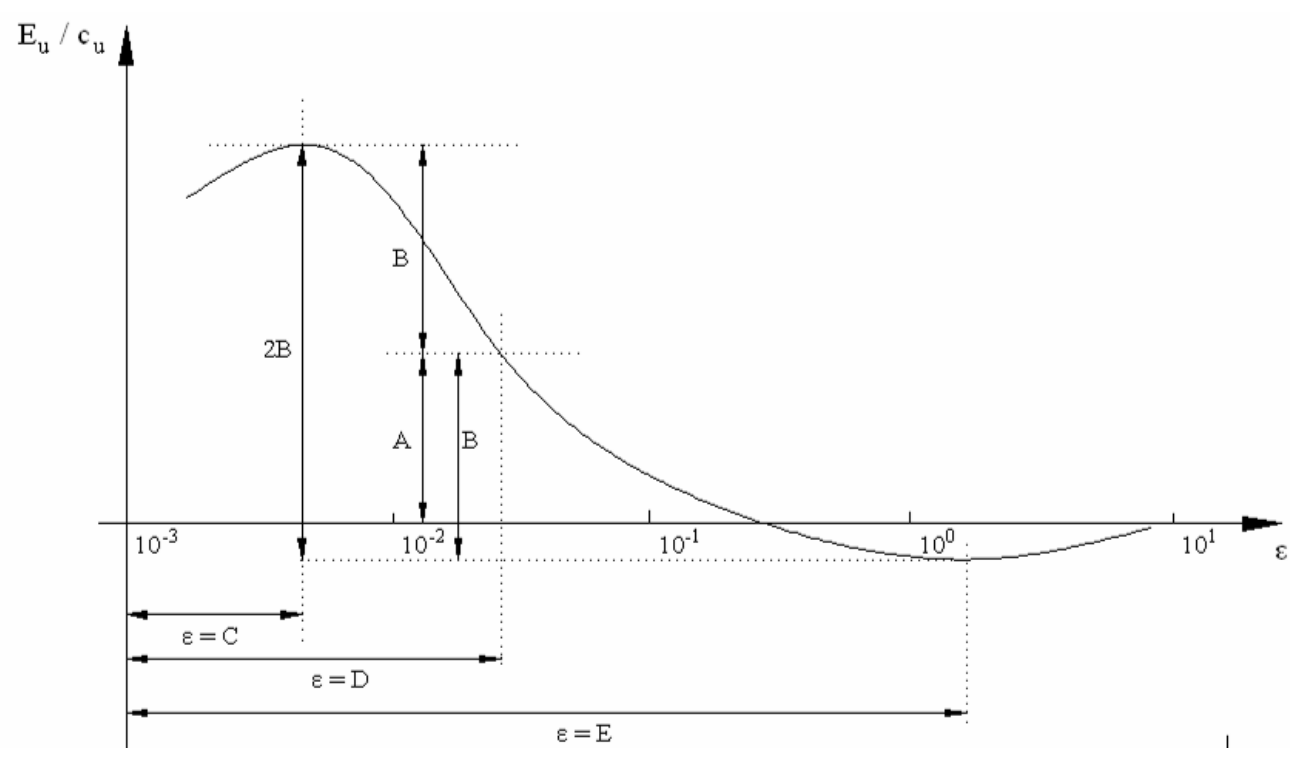

Figure 6. Jardine model - secant stiffness defined as a logarithmic function of strain [14].

The last action is the definition of the constitutive stresses. After the calculation of the actual E-modulus, the new stiffness matrix is determined and the trial stresses are calculated as follows:

$$
{ }^{\text {pred }} \sigma_{n+1}=\sigma_{\mathrm{n}}+D \epsilon_{n+1} \text {. }
$$

These stresses are one of the main inputs into the user-defined subroutine STRESS_INTEGRATION. This complex subroutine is the core element of the implementation and the backward return-mapping algorithm is implemented there. The first step in the subroutine is the check of the trial stresses. The JPHS model contains three different yield surfaces (Willam-Warnke yield surface $F_{\mathrm{s}}$, Cap yield surface $F_{\mathrm{c}}$ and Tension cut-off yield surface $F_{\mathrm{t}}$ ), and therefore the trial stresses can occur in 6 different regions:

- elastic region $\left(F_{\mathrm{s}}<0, F_{\mathrm{c}}<0\right.$ and $\left.F_{\mathrm{t}}<0\right)$;

- Willam-Warnke region $\left(F_{\mathrm{s}} \geq 0, F_{\mathrm{c}}<0\right.$ and $\left.F_{\mathrm{t}}<0\right)$;

- cap region $\left(F_{\mathrm{s}}<0, F_{\mathrm{c}} \geq 0\right.$ and $\left.F_{\mathrm{t}}<0\right)$;

- tension cut-off region $\left(F_{\mathrm{s}}<0, F_{\mathrm{c}}<0\right.$ and $\left.F_{\mathrm{t}} \geq 0\right)$;

- Willam-Warnke and Tension cut-off region $\left(F_{\mathrm{s}} \geq 0\right.$, $F_{\mathrm{c}}<0$ and $\left.F_{\mathrm{t}} \geq 0\right)$;

- Willam-Warnke and Cap region $\left(F_{\mathrm{s}} \geq 0, F_{\mathrm{c}} \geq 0\right.$ and $\left.F_{\mathrm{t}}<0\right)$.

If the trial stress occurs in the elastic region $\left(F_{\mathrm{s}}<0\right.$, $F_{\mathrm{c}}<0$ and $F_{\mathrm{t}}<0$ ), then the strain increment is elastic and the trial stress is the real stress for the increment:

$$
\sigma_{n+1}={ }^{\text {pred }} \sigma_{n+1} .
$$

If the trial stress occurs in other regions $\left(F_{\mathrm{s}} \geq 0\right.$ or $F_{\mathrm{c}} \geq 0$ or $F_{\mathrm{t}} \geq 0$ ), then the trial stress is an inadmissible stress state and return-mapping algorithm is called. The general implementation of the return mapping algorithm is as follows [22]:

(1.) Calculate the starting point: (a) calculate the derivatives (according to the region)

$$
\begin{aligned}
{ }^{n+1} n_{m n} & =\left(\frac{\partial F}{\partial \sigma_{m n}}\right)_{n+1}, \\
{ }^{n+1} m_{p q} & =\left(\frac{\partial Q}{\partial \sigma_{p q}}\right)_{n+1} ;
\end{aligned}
$$

(b) update the plastic multiplier $\lambda$ (yield function ${ }^{\text {pred }} F$ according to the region)

$$
\mathrm{d} \lambda^{(0)}=\frac{{ }^{\text {pred }} F}{\operatorname{pred}_{n_{m n}} D_{i j k l}{ }^{\text {pred }} m_{p q}-h_{\kappa}} ;
$$

(c) update stress and state variable

$$
\begin{gathered}
{ }^{(n+1)} \sigma_{m n}^{(0)}={ }^{\text {pred }} \sigma_{m n}-\mathrm{d} \lambda^{(0)} D_{m n p q}{ }^{\text {pred }} m_{p q}, \\
{ }^{(n+1)} \kappa^{(0)}={ }^{\text {pred }} \kappa+\mathrm{d} \lambda^{(0)} h_{\kappa}
\end{gathered}
$$

(2.) Calculate Backward Euler algorithm: DO WHILE ${ }^{n+1} F^{(i)}<$ tol

(a) calculate the yield function ${ }^{n+1} F^{(i)}$ (according to the region)

$$
{ }^{n+1} F^{(i)}=f\left({ }^{n+1} \sigma_{i j}^{(i)},{ }^{n+1} \kappa^{(i)}\right) ;
$$

(b) calculate the derivatives (according to the region)

$$
\begin{gathered}
{ }^{n+1} n_{m n}^{(i)}=\left(\frac{\partial F}{\partial \sigma_{m n}}\right)_{n+1}, \\
{ }^{n+1} m_{k l}^{(i)}=\left(\frac{\partial Q}{\partial \sigma_{k l}}\right)_{n+1}, \\
\left.\frac{\partial m_{k l}}{\partial \sigma_{m n}}\right|_{n+1} ^{(i)},\left.\quad \frac{\partial m_{k l}}{\partial \kappa}\right|_{n+1} ^{(i)} ;
\end{gathered}
$$




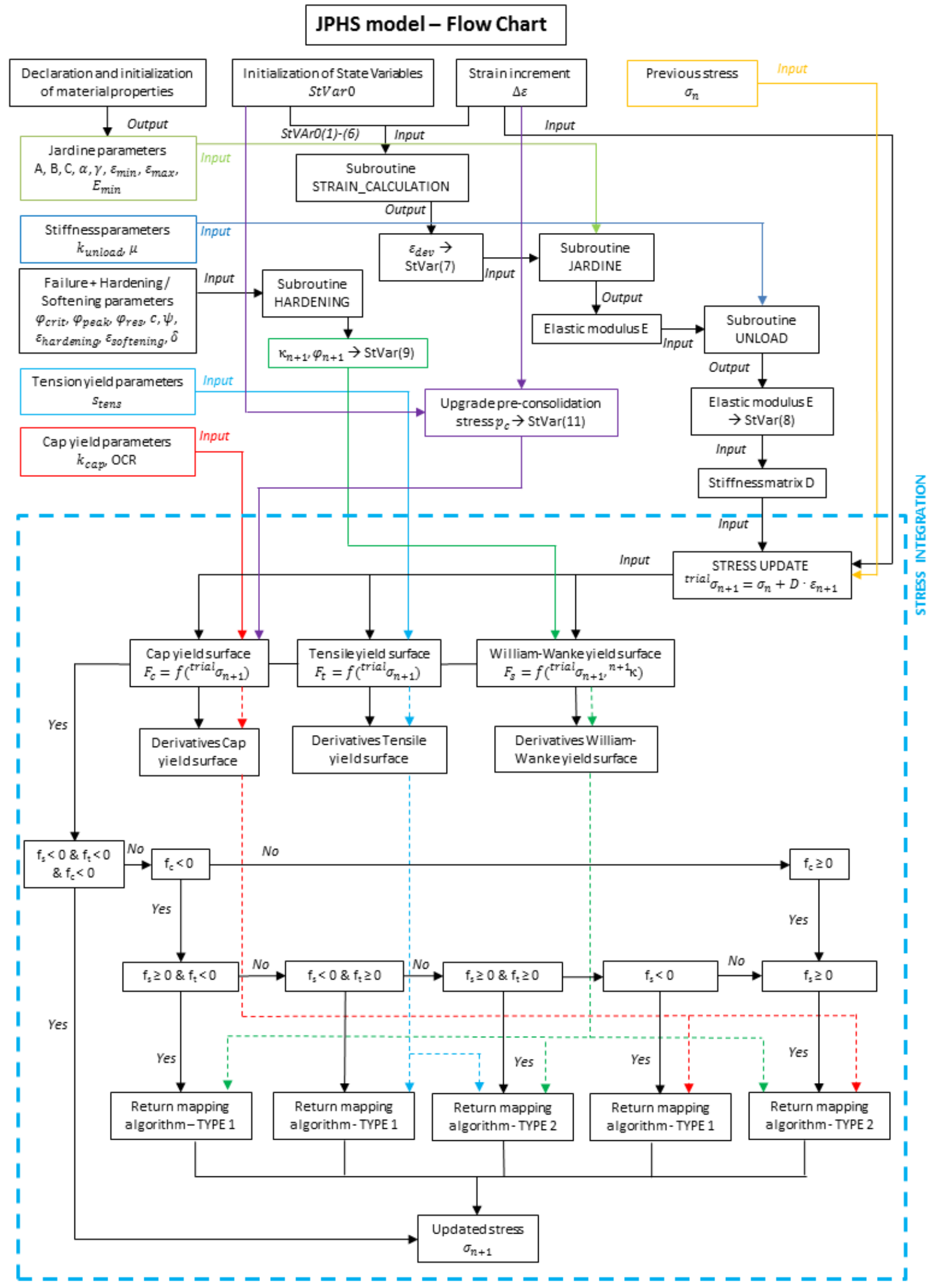

Figure 7. JPHS model - flow chart. 
(c) update the plastic multiplier $\lambda$ (yield function ${ }^{\text {pred }} F$ according to the region)

$$
\mathrm{d} \lambda^{(i+1)}=\frac{{ }^{n+1} F^{(i)}-{ }^{n+1} n_{m n}^{(i)}{ }^{\text {old }} r_{i j}\left({ }^{n+1} T_{i j m n}\right)^{-1}}{D_{3}-{ }^{n+1} h_{\kappa}},
$$

where

$$
\begin{gathered}
D_{3}={ }^{n+1} n_{m n}^{(i)} D_{i j k l}{ }^{n+1} m_{k l}\left({ }^{n+1} T_{i j m n}\right)^{-1} \\
{ }^{n+1} T_{i j m n}=\delta_{i m} \delta_{n j}+\left.\lambda^{(i)} D_{i j k l} \frac{\partial m_{k l}}{\partial \sigma_{m n}}\right|_{n+1} ^{(i)}, \\
r_{i j}=\sigma_{i j}-\left({ }^{\text {pred }} \sigma_{i j}-\lambda^{(i)} D_{i j k l}{ }^{n+1} m_{k l}^{(i)}\right)
\end{gathered}
$$

(d) update stress and state variable

$$
\begin{aligned}
& { }^{(n+1)} \sigma_{m n}^{(i+1)}={ }^{\text {pred }} \sigma_{m n}-\mathrm{d} \lambda^{(i)} D_{m n p q}{ }^{n+1} m_{p q}, \\
& { }^{(n+1)} \kappa^{(i)}={ }^{\text {pred }} \kappa+\mathrm{d} \lambda^{(i)} h_{\kappa} .
\end{aligned}
$$

(e) $i=i+1$

END DO

\section{VAlidATion OF THE MODEL}

The following chapter is focused on the validation and verification of theJPHS model. The basic soil tests (the triaxial test and oedometer test) are simulated by using the numerical analyses and the results are compared with the real measured data from laboratory tests done on the Brno clay [15].

\subsection{The triaxial test}

The 2D analysis (PLAXIS v.2016) of the triaxial test is simulated by using the axisymmetric model. The input parameters for the JPHS model are summarized in Table 1 and Table 4 . The coarseness of the mesh, geometry and dimensions of the model are presented in Figure 8 The left and the bottom boundaries are fixed in horizontal and vertical directions respectively. The isotropic / axial loading is represented by a distributed load and is applied on the top and right boundary. The modelling sequence is as follows:

(1.) Initial conditions.

(2.) Isotropic loading (The loads applied to the top and right boundary are activated, the undrained behaviour is ignored. After the isotropic loading, the prescribed displacements are set to zero).

(3.) Axial compression to the failure (The load applied to the top is increased to a value which causes the failure, the undrained behaviour is active).

Figure 9 and 10 presents the results of the triaxial tests for different values of initial stress conditions $(275,500$ and $750 \mathrm{kPa})$. The results confirm that the JPHS model predicts a good match with the laboratory data. Slightly over predicted is only the peak strength for $750 \mathrm{kPa}$, but this initial value corresponds

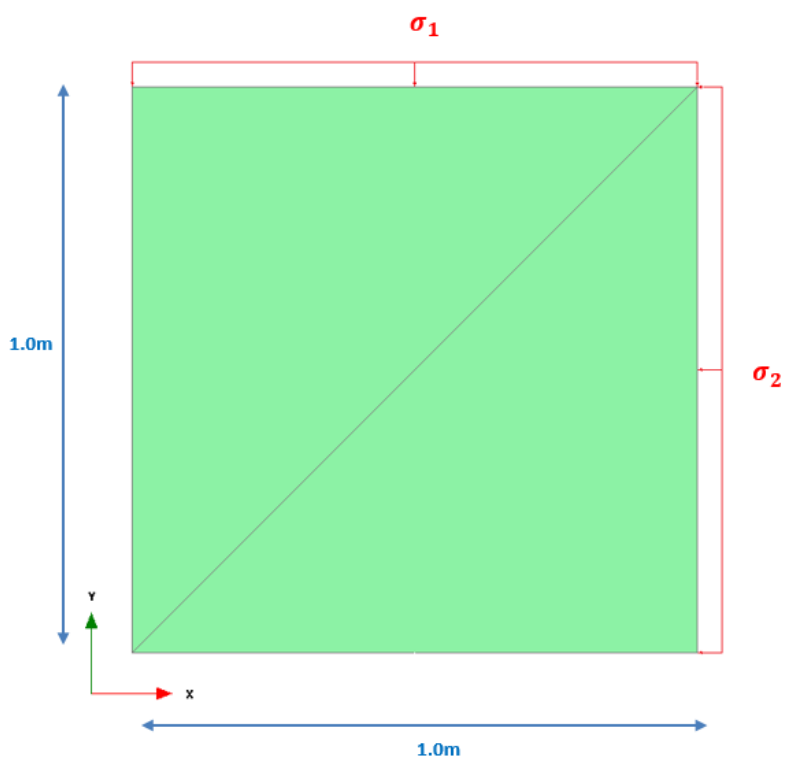

Figure 8 . The Triaxial Test $-2 \mathrm{D}$ model.

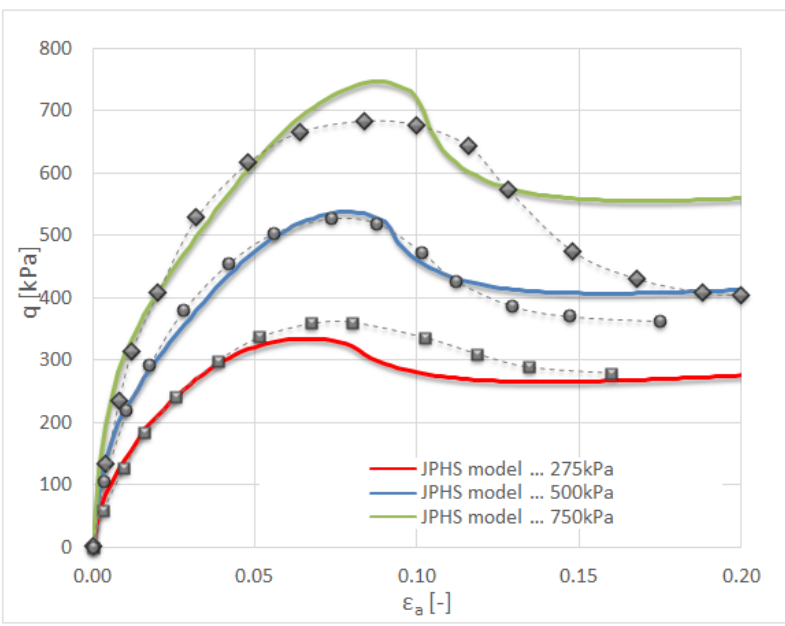

Figure 9. The Triaxial Test Results - strain versus deviatoric stress, lab. data from [15].

to the depth of approximately $100 \mathrm{~m}$ that is not a common area for the construction of geotechnical structures.

The comparison of water pressure development is shown in Figure 11 and again confirms a good match. The curve's shape is almost identical with the laboratory data and the slight underprediction of maximum excess pore pressure is only $15 \%$.

\subsection{Oedometer test}

The numerical simulation of the oedometer test is done by a 3D analysis (PLAXIS v.2013). The input paramters for the JPHS model are summarized in Table 1 and Table 4 The coarseness of the mesh, geometry and dimensions of the model are presented in Figure 12. The side boundaries are fixed in horizontal directions; the vertical fixities are used on the bottom 


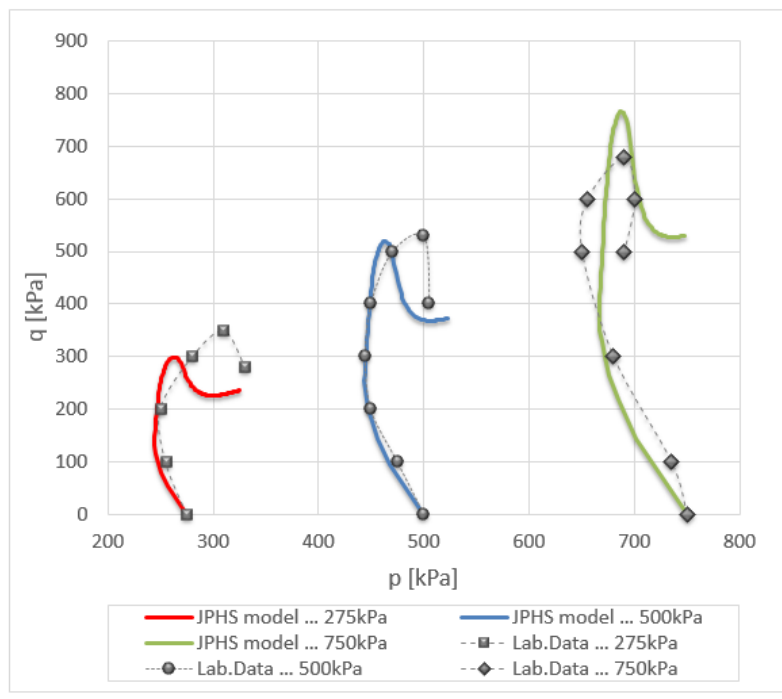

Figure 10. The Triaxial Test Results - hydrostatic pressure versus deviatoric stress, lab. data from [15].

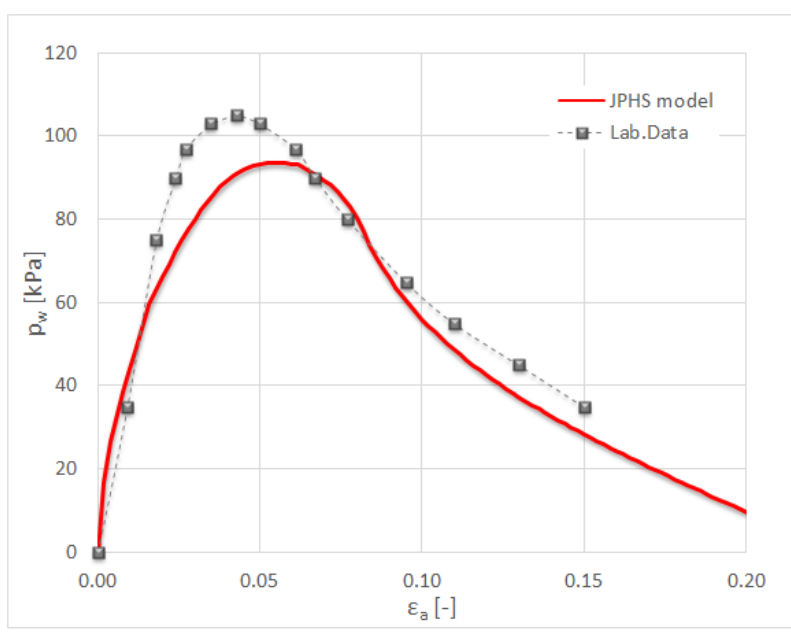

Figure 11. The Triaxial Test Results - strain versus water pressure, lab. data from [15].

side. The axial load $\sigma_{1}$ is represented by a distributed load on the top plane. The modelling sequence is as follows:

(1.) Initial conditions.

(2.) Axial compression (the load applied on the top is gradually increased).

(3.) Unloading (the load applied on the top is gradually decreased).

The results are shown in Figure 13 and confirm a good match between the JPHS model simulation and the laboratory data for both the loading and unloading stages. If the absolute values of axial strain are compared, then the JPHS model slightly underestimates the maximum value (approx. 10\%).

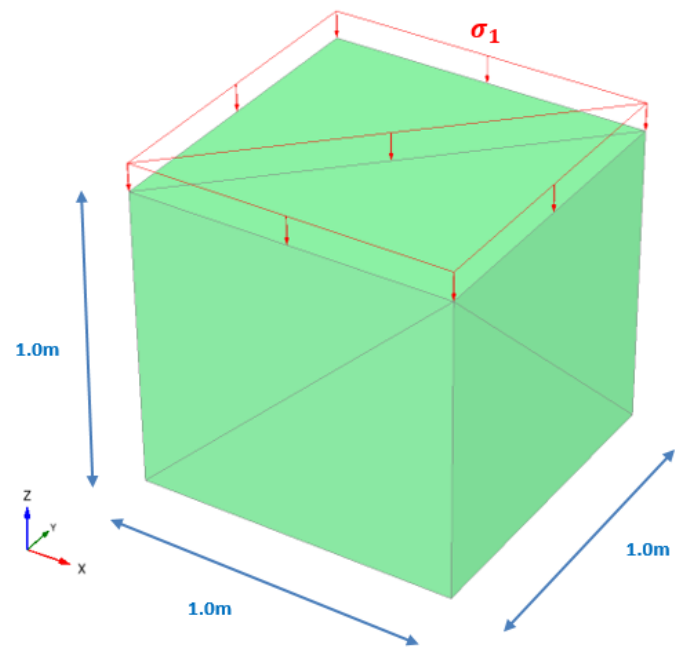

Figure 12. Oedometer Test $-3 \mathrm{D}$ model.

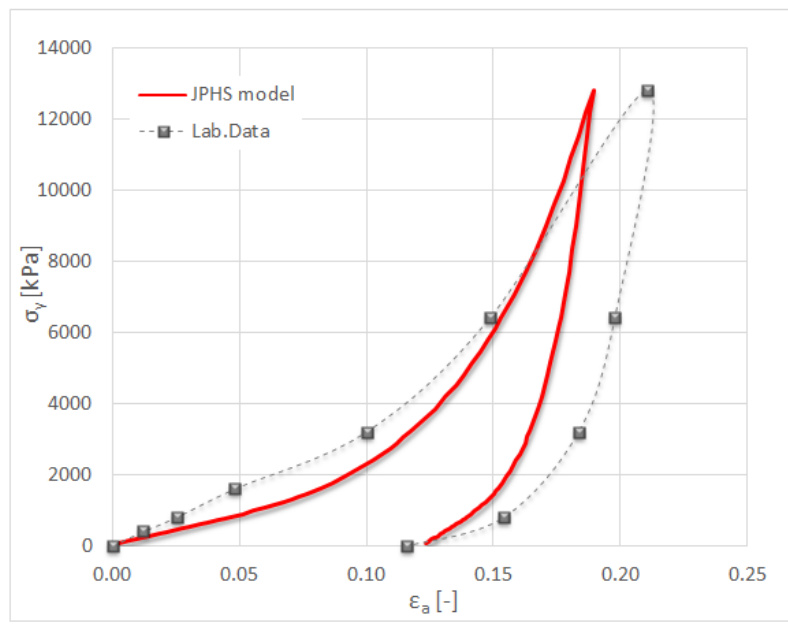

Figure 13. Oedometer Test Results - strain versus stress, lab. data from 15.

\section{Practical use of the model - NUMERICAL MODELLING OF TUNNEL EXCAVATION}

The 3D numerical analysis of the shallow tunnel in stiff clay is performed to verify the JPHS model and to compare the results calculated by this model with the real data from the geotechnical monitoring. For the calculation, the Kralovopolske tunnels (exploration adit) is chosen. The Kralovopolske tunnels are a part of the ring road of Brno town in the Czech Republic and are excavated in difficult geological conditions. The overburden varies between $6 \mathrm{~m}$ to $22 \mathrm{~m}$, the tunnels are excavated in Brno clay and there is an urban area on the surface.

\subsection{Model Discretization AND BOUNDARY CONDITIONS}

The numerical analysis is carried out in the software PLAXIS 3D v.2013. Model represents $100 \mathrm{~m}$ wide, 


\begin{tabular}{llccc}
\hline & & Loess and clay loams & Sand Deposits & Stiff Clay \\
\hline Unit weight & $\gamma\left[\mathrm{kNm}^{-3}\right]$ & 19.0 & 19.0 & 18.0 \\
\hline E-modulus & $\mathrm{E}[\mathrm{MPa}]$ & 10 & 65 & 15 \\
\hline Poisson's ratio & $\nu[-]$ & 0.35 & 0.35 & 0.40 \\
\hline Cohesion & $\mathrm{c}^{\prime}[\mathrm{kPa}]$ & 10 & 5.0 & 5.0 \\
\hline Friction angle & $\phi^{\prime}\left[{ }^{\circ}\right]$ & 20 & 30 & 26 \\
\hline Dilatation angle & $\left.\psi^{\circ}{ }^{\circ}\right]$ & 4.0 & 8.0 & 1.0 \\
\hline
\end{tabular}

TABLE 1. MC model — geotechnical parameters.

\begin{tabular}{cccccc}
\hline $\begin{array}{c}\text { Cam-Clay } \\
\text { swelling } \\
\text { index } \\
\kappa[-]\end{array}$ & $\begin{array}{c}\text { Cam-Clay } \\
\text { compression } \\
\text { index } \\
\lambda[-]\end{array}$ & $\begin{array}{c}\text { Tangent of } \\
\text { critical state } \\
\text { line }\end{array}$ & $\begin{array}{c}\text { Initial void } \\
\text { ratio }\end{array}$ & $\begin{array}{c}\text { Poisson's } \\
\text { ratio }\end{array}$ \\
\hline Stiff Clay & 0.2 & 0.09 & 1.55 & $\mathrm{e}[-]$ & $\nu_{\mathrm{ur}}[-]$ \\
\hline
\end{tabular}

TABle 2. Modified Cam Clay model - geotechnical parameters.

$48 \mathrm{~m}$ high and $90 \mathrm{~m}$ deep section of the soil mass, where the top boundary of the model represents the ground surface. The bottom and the side model boundaries are set at a distance required to reliably predict stress redistribution and ground deformation around the tunnel. The tunnel has a triangular shape with $4.8 \mathrm{~m}$ width and $4.2 \mathrm{~m}$ height and the crown of the tunnel is situated in a stiff clay approx. $22 \mathrm{~m}$ under the surface. The model geometry including the mesh and coordination system is presented in Figure 14 . The model boundary conditions are set that the vertical displacement is fixed at the bottom boundary and the horizontal displacements are fixed at the side boundaries.

\subsection{Ground PRoperties AND PRIMARY STRESS CONDITIONS}

The area of Kralovopolske tunnels is formed by Miocene marine deposits of the Carpathian fore deep. The main geological strata, taken from the ground surface to bedrock, are loess and clay loams with a thickness between $3-10 \mathrm{~m}$, followed by the layer of sand deposits (thickness approx. $10 \mathrm{~m}$ ) and stiff clay (locally called Brno clay). The thickness of this clay is expected to be several hundreds of meters and most of the route of the tunnels is located there. The ground water level is connected with a sand layer and observed in the depth of $13-20 \mathrm{~m}$.

According to the study done by Svoboda et al. [15], material properties of the loams and sand deposits have an only small influence on the prediction of surface settlement, and therefore they are modelled only by using the Mohr-Coulomb model in this study. However, the stiff clay is modelled using the JPHS model and its prediction is then compared with the prediction calculated by the Mohr-Coulomb model, Modified Cam Clay model and Hardening Small Strain

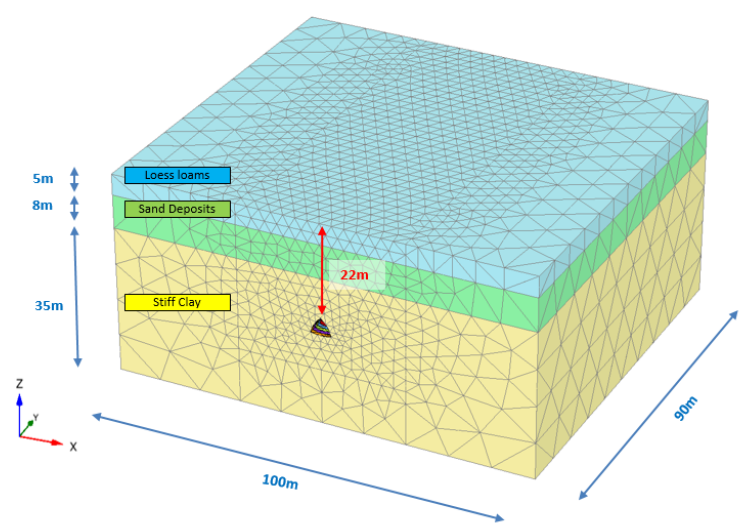

Figure 14. Model geometry.

model. The model parameters are calibrated based on laboratory tests [15], which have been carried out during the site investigation. The parameters used for the numerical analysis are summarized in Table 1 to Table 4 and the calibration of the stiff clay for the JPHS model is shown in Figure 9. Figure 11. Figure 13 and Figure 15 . The calibration of other models is mentioned in [23].

To set the initial stress conditions, it is necessary to determine the coefficient of earth pressure $K_{0}$. The Brno clay can be characterized as over-consolidated clay with $O C R=6.5$ [15]. By using the formula by Mayne and Kulhawy [24] the $K_{0}$ coefficient is:

$$
\begin{aligned}
& K_{0}=(1-\sin \phi) O C R^{\sin \phi} \\
& \quad=(1-\sin 26.5) 6.5^{\sin 26.5}=1.25 .
\end{aligned}
$$

\subsection{Primary Lining AND MODElling StageS} The Kralovopolske exploration adit is excavated by the New Austrian Tunnelling Method (NATM) with 


\begin{tabular}{cccccc}
\hline & $E_{50}^{\text {ref }}[\mathrm{MPa}]$ & $E_{\text {oed }}^{\text {ref }}[\mathrm{MPa}]$ & $\begin{array}{c}\text { E-modulus } \\
E_{\mathrm{ur}}^{\mathrm{ref}}[\mathrm{MPa}]\end{array}$ & $G_{0}^{\mathrm{ref}}[\mathrm{MPa}]$ & $\gamma_{0.7}[-]$ \\
\hline Stiff Clay & 3.0 & 2.9 & 9.0 & 11.0 & $2.0 \cdot 10^{-4}$ \\
\hline & $\begin{array}{c}\text { Power stress } \\
\text { dependency } \\
m[-]\end{array}$ & $\begin{array}{c}\text { Poisson's ratio } \\
\nu_{\text {ur }}[-]\end{array}$ & $\begin{array}{c}K_{0} \text { value for } \\
\text { NC } \\
K_{0}^{\mathrm{NC}}[-]\end{array}$ & $\begin{array}{c}\text { Reference } \\
\text { pressure } \\
p_{\text {ref }}[\mathrm{kPa}]\end{array}$ \\
\hline Stiff Clay & 1.0 & 0.2 & 0.54 & 100 \\
\hline
\end{tabular}

TABLE 3. HSS model - geotechnical parameters.

\begin{tabular}{llc}
\hline & & Stiff clay \\
\hline Jardine Stiffness & $\mathrm{A}[-]$ & 180 \\
\cline { 2 - 3 } Parameters & $\mathrm{B}[-]$ & 165 \\
\cline { 2 - 3 } & $\mathrm{C}[-]$ & $1.7 \cdot 10^{-5}$ \\
\cline { 2 - 3 } & $\alpha[-]$ & 0.85 \\
\cline { 2 - 3 } & $\gamma[-]$ & 1.05 \\
\cline { 2 - 3 } & $\epsilon_{\text {min }}[-]$ & $1.701 \cdot 10^{-5}$ \\
\cline { 2 - 3 } & $\epsilon_{\text {max }}[-]$ & 0.02 \\
\hline Critical Friction angle & $\left.\phi_{\text {crit }}^{\prime}{ }^{\circ}\right]$ & 15.0 \\
\hline Peak Friction angle & $\left.\phi_{\text {peak }}^{\prime}{ }^{\circ}\right]$ & 28.0 \\
\hline Residual Friction angle & $\phi_{\text {res }}^{\prime}\left[^{\circ}\right]$ & 18.0 \\
\hline Hardening constant & $\epsilon_{\text {hardening }}[-]$ & 0.07 \\
\hline Softening constant & $\epsilon_{\text {softening }}[-]$ & 0.04 \\
\hline Hard./soft. constant & $\delta[-]^{\circ}$ & 1.075 \\
\hline Unloading coefficient & $k_{\text {unload }}[-]$ & 2.7 \\
\hline Cap coefficient & $k_{\text {cap }}[-]$ & 0.45 \\
\hline
\end{tabular}

TABLE 4. JPHS model - geotechnical parameters.

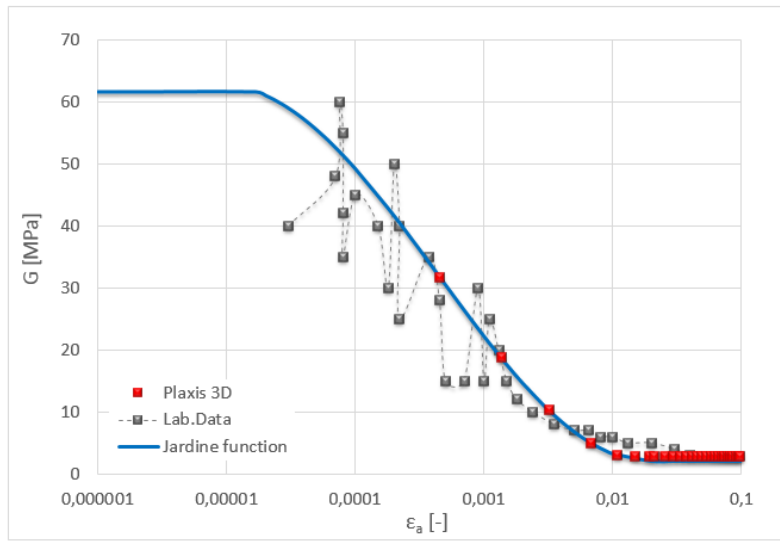

FIGURE 15. JPHS model calibration- small strain stiffness, laboratory data from [15].

a full-face adit excavation. The numerical analysis corresponds to a construction process with the round length of $1.0 \mathrm{~m}$ that leads to 90 calculation phases. Each phase represents excavation progress of $1.0 \mathrm{~m}$ and installation of the tunnel lining in period of 8 hours. The tunnel lining consists of $100 \mathrm{~mm}$ of sprayed concrete, lattice girders ( $1 \mathrm{~m} \mathrm{span})$ and wire meshes. The lining is modelled using shell elements, which are capable of taking normal forces and bending moments. The lining is directly connected to the soil mass and is modelled as linearly elastic. To simulate the influence of the lattice girders on the stiffness of the lining, the homogenization of a steel-concrete lining is done according to [25]. This procedure converses the cross-section of a lining consisting of two components with different E-modulus to a substitute-homogenized cross-section with only one modulus of elasticity. To simulate the increase in stiffness of the sprayed concrete with the time, the Young's modulus of shotcrete is updated in the construction stage process and is based on the Menschke equation [26]:

$$
E_{\mathrm{t}}=\beta_{\mathrm{Et}} E_{28}
$$

where

$$
\beta_{\mathrm{Et}}= \begin{cases}0.0468 t-0.00211 t^{2} & \text { if } t<1 \text { day } \\ \beta_{\mathrm{Et}}=\left(0.9506+\frac{32.89}{t-6}\right)^{-0.5} & \text { if } t \geq 1 \text { day }\end{cases}
$$

\subsection{Results of the NUMERICAL ANALYSiS}

Four 3D analyses are carried out to determine the effect of the material models on the deformation of the ground during the excavation of the adit in stiff clay. Three analyses are done using the standard material models included in software PLAXIS (Mohr Coulomb, Modified Cam-Clay and Hardening Small Strain model) while the fourth analysis is done using the JPHS model. In the following chapter, the results of all analyses are discussed and compared with the real data from geotechnical monitoring.

Figure 16] presents the surface settlement after the full excavation of the adit. The results show that the settlement trough calculated by the MC model has a totally unrealistic shape. The vertical displacement above the tunnel is lower than at the certain distance from the axis. This phenomenon is caused by a high value of $K_{0}$ and it is evident that the MC model is not suitable for a numerical modelling of the overconsolidated soils. The other models predict better shape of settlement though and differs mainly in its width 


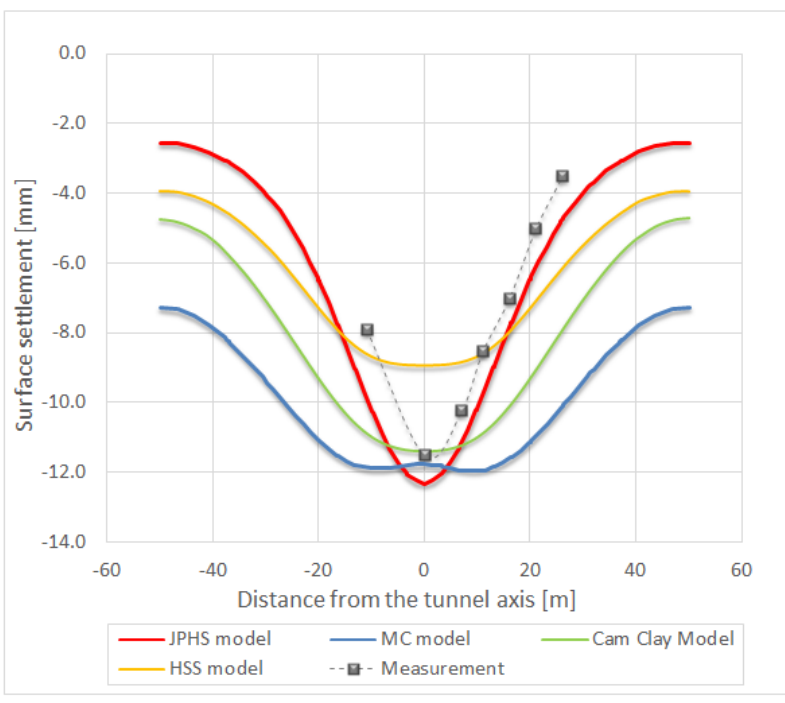

Figure 16. The settlement trough after full profile excavation, monitoring data from [11].

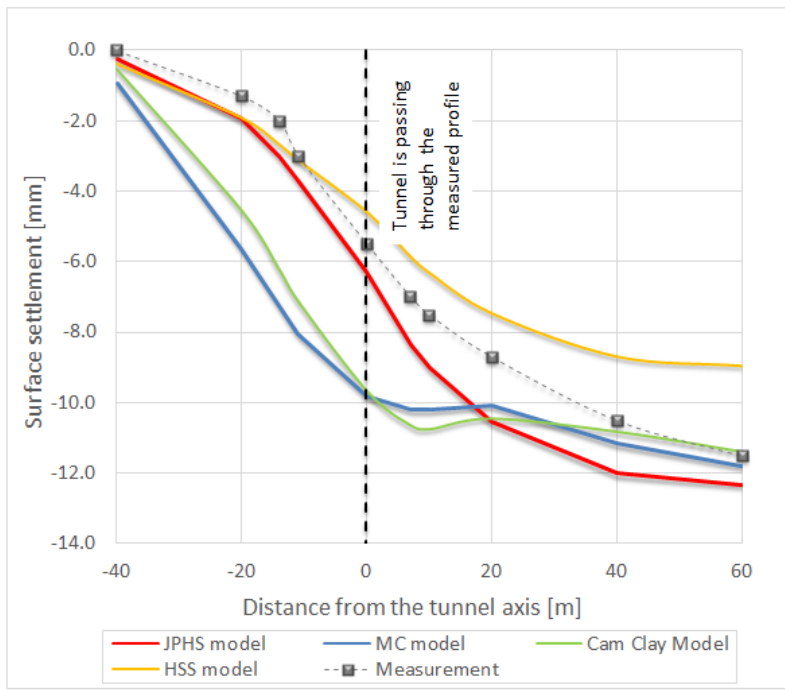

Figure 17. Development of the settlement in the longitudinal direction, monitoring data from [15].

and depth. The closest results to the real monitored data are calculated by the JPHS model. If we look at the absolute values of the surface settlement, we can clearly see that the JPHS model almost predicts the same values (difference around 5\%), while the HSS model underestimates the vertical displacement by more than $25 \%$. Also, the width of the settlement trough calculated by the JPHS model is almost two times more accurate than the one predicted by the Modified Cam-Clay model.

Another interesting results can be observed when the development of the settlement in the longitudinal direction is compared (see Figure 17).

The development of the settlement in the longitudinal direction calculated by the MC and Modified Cam-Clay model has an unrealistic shape. The models are predicting that $80 \%$ of the deformation will occur before the adit face pass through the measured profile.

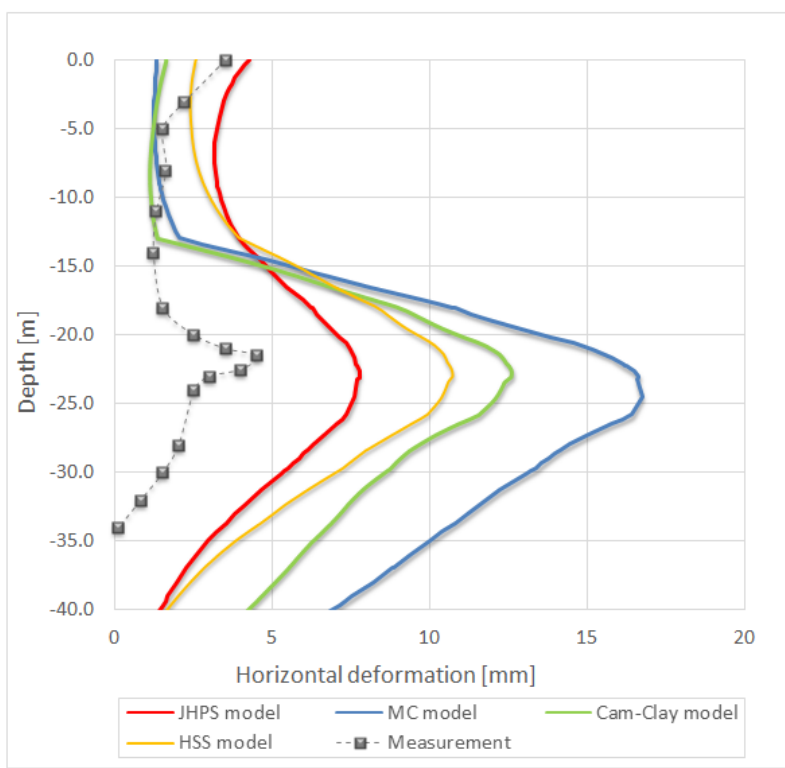

FiguRE 18. Horizontal displacement after full profile excavation, monitoring data from [15].

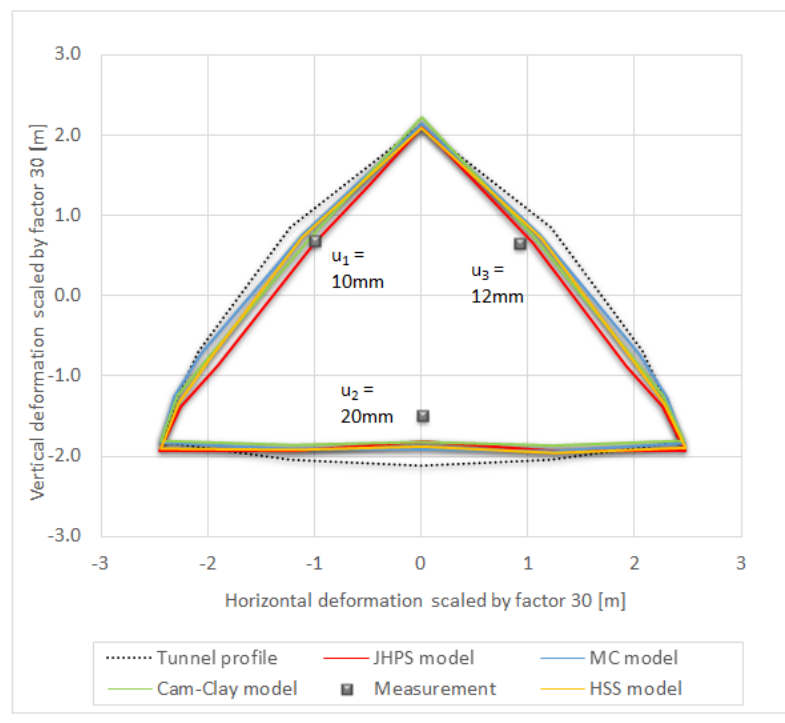

Figure 19. Deformations of the adit lining, monitoring data from [15].

One of the reasons for this behaviour is that the MC and Modified Cam-Clay model does not contain the non-linear small-strain behaviour of soils. However, this feature is implemented in the HSS and the JPHS model and especially the JPHS model fits very well with the monitoring data.

The similar results can also be observed for the horizontal displacement as presented in Figure 18

The JPHS model is closest to the real measured data. The difference is higher (approx. 50\%), but one of the reasons can be the anisotropy of Brno Clay (mentined by [27]), which is not implemented in the model. The JPHS model is also the only model that correctly simulates the increase of the horizontal displacement near to the ground surface.

The good match is also indicated when comparing 
the deformations of the adit lining. The differences between the material models are, in this case, not so significant but the JPHS model is still closest to the reality (see Figure 19.

\section{Conclusions}

The presented results show that the choice of the material model has a significant influence on the correct modelling of the soil behaviour. The commonly used Mohr-Coulomb is not appropriate for the numerical analysis in the overconsolidated clay and it is necessary to use advanced material models. The presented JPHS model demonstrates that is able to quite precisely simulate behaviour of the soils and with proper calibration of input parameters, it is possible to predict the correct displacements of the ground during excavation.

\section{LIST OF SYMBOLS}

$\alpha_{\text {DP }} \quad$ Drucker-Prager coefficient [-]

$\delta \quad$ Hard./soft. constant based on the triaxial test [-]

$\epsilon_{\mathrm{a}}$ Axial strain [-]

$\epsilon_{\text {dev }}$ Deviatoric strain invariant $[-]$

$\epsilon_{\text {hardening }}$ Hardening constant based on the triaxial test $[-]$

$\epsilon_{\mathrm{n}} \quad$ Strain tensor $[-]$

$\epsilon_{\text {softening }}$ Softening constant based on the triaxial test [-]

$\epsilon_{\mathrm{v}} \quad$ Volumetric strain [-]

$\mathrm{d} \epsilon^{\mathrm{p}} \quad$ Plastic strain scalar [-]

$\kappa$ Hardening/softening variable [-]

$\lambda$ Plastic multiplier [-]

$\phi^{\prime}$ Actual friction angle [rad]

$\phi_{\text {peak }}^{\prime}$ Peak friction angle [rad]

$\phi_{\text {res }}^{\prime}$ Residual friction angle [rad]

$\psi$ Dilatation angle [rad]

$\sigma_{\mathrm{m}}$ Mean stress pressure $[\mathrm{kPa}]$

$\sigma_{\mathrm{n}} \quad$ Stress tensor $[\mathrm{kPa}]$

$\theta$ Loge angle [rad]

$c_{\mathrm{u}} \quad$ Undrained shear strength $[\mathrm{kPa}]$

$k_{\text {cap }}$ Cap coefficient [-]

$k_{\text {unload }}$ Unload coefficient [-]

$p$ Hydrostatic stress [kPa]

$p_{\mathrm{c}}$ Pre-consolidation stress $[\mathrm{kPa}]$

$q$ Deviatoric stress $[\mathrm{kPa}]$

$r_{\mathrm{c}}$ Distance from the hydrostatic axis to the failure surface at the compressive meridian $[\mathrm{m}]$

$r_{\mathrm{t}}$ Distance from the hydrostatic axis to the failure surface at the tension meridian $[\mathrm{m}]$

\section{$A, B, C, \alpha, \gamma, \epsilon_{\min }, \epsilon_{\max } \quad$ Jardine material model constants} based on the triaxial test $[-]$

$D$ Stiffness matrix [-]

$E_{\mathrm{t}}$ Young's modulus of sprayed concrete in time [kPa]

$E_{28}$ Young's modulus of sprayed concrete after 28 days $[\mathrm{kPa}]$

$E_{\text {unload }}$ Unloading Young's modulus $[\mathrm{kPa}]$
$E_{\mathrm{u}}$ Secant Young's modulus $[\mathrm{kPa}]$

$E_{\text {ut }}$ Tangent Young's modulus [kPa]

$F \quad$ Yield function [-]

$K$ Bulk modulus $[\mathrm{kPa}]$

OCR Over consolidation ratio $[-]$

$Q$ Potential function [-]

\section{ACKNOWLEDGEMENTS}

This work was supported by the Grant Agency of the Czech Technical University in Prague, grants SGS15/045/OHK1/1T/11 and SGS16/051/OHK1/1T/11.

\section{REFERENCES}

[1] G.R.Dasari, C.G.Rawlings, M.D.Bolton. Numerical modelling of a natm tunnel construction in london clay. In Geotechnical Aspects of Underground Construction in Soft Ground, Rotterdam, pp. 491-496. 1996.

[2] P.A.Vermeer, P. Bonnier, S.C.Moller. On a smart use of $3 \mathrm{~d}$-fem in tunnelling. In Proceedings of the 8th International Symposium on Numerical Models in Geomechanics - NUMOG VIII, Rome, Italy, pp. 361-366. 1996. DOI:10.1201/9781439833797-c52

[3] M.Dolezalova. Approaches to numerical modelling of ground movements due to shallow tunnelling. In Proc. 2nd Int. Conference on Soil Structure Interaction in Urban Civil Engineering, ETH Zurich, pp. 365-376. 2002.

[4] C. Ng, G. Lee. Three-dimensional ground settlements and stress-transfer mechanisms due to open-face tunnelling. Canadian Geotechnical Journal 42(4):1015-2029, 2005. DOI:10.1139/t05-025

[5] L.Vydrova, J.Vesely. Optimization of the numerical modeling utilization for the design of undeground structures. In Geotechnical Engineering: New horizons. 2011. ISBN 978-1-60750-807-6. 2011.

[6] S. Maras-Dragojevic. Analysis of ground settlement caused by tunnel construction. Gradevinar 64(7):573-581, 2012.

[7] A. Lambrughi, L. Rodriguez, R. Castellanza. Development and validation of a $3 \mathrm{~d}$ numerical model for tbm-epb mechanised excavations. Computers and Geotechnics 40:97-113, 2012. DOI:http://dx.doi.org/10.1016/j.compgeo.2011.10.004

[8] T.Janda, M.Sejnoha, J.Sejnoha. Modeling of soil structure interaction during tunnel excavation: An engineering approach. Advances in Engineering Software 62-63:51-60, 2013. DOI:http://dx.doi.org/10.1016/j.advengsoft.2013.04.011

[9] J.Bartak, J.Pruska, M.Hilar. Probability analysis of the effect of input parameters on the mrazovka tunnel deformations modelling. Tunel 11(3):27-33, 2002.

[10] T.Svoboda, , M.Hilar. Probabilistic analyses of tunnel loads using variance reduction. Proceedings of the Institution of Civil Engineers - Geotechnical Engineering 168(4):348-357, 2015. DOI:http://dx.doi.org/10.1680/geng.14.00062

[11] D.Masin. 3d modeling of an natm tunnel in high k0 clay using two different constitutive models. Journal of Geotechnical and Geoenvironmental Engineering 135:1326-1335, 2009. DOI:10.1061/(ASCE)GT.1943-5606.0000017 
[12] D.Masin, I.Herle. Numerical analyses of a tunnel in london clay using different constitutive models. In Geotechnical aspects of underground construction in soft ground, At Amsterdam, pp. 795-801. 2015. DOI:10.1201/NOE0415391245.ch81

[13] T. Benz. Small-Strain Stiffness of Soils and its Numerical Consequences. Ph.D. thesis, University of Stuttgart, 2010.

[14] R. Jardine, D. Potts, A. Fourie, J. Burland. Studie of the influence of non-linear stress-strain characteristics in soil-structure interaction. Geotechnique 36(3):377-396, 1986. DOI:10.1680/geot.1986.36.3.377.

[15] T. Svoboda. Numericky model NRTM tunelu v tuhem jilu. Ph.D. thesis, Charles University in Prague, 2010.

[16] A. Gasparre. Advanced Laboratory Characterisation of London Clay. Ph.D. thesis, Imperial College London, 2005.

[17] K.J.Willam, E.P.Warnke. Constitutive model for triaxial behavior of concrete. In International Association for Bridges and Structural Engineering Proceedings. Bergamo, Italy, vol. 19. 1975.

[18] A. Prashant. Three-Dimensional Mechanical Behavior of Kaolin Clay with Controlled Microfabric Using True Triaxial Testing. Ph.D. thesis, University of Tennessee, 2004.

[19] D. Drucker, W. Prager. Soil mechanics and plastic analysis or limit design. Quarterly of applied mathematics 10(2):157-165, 1952.
[20] M. Jirasek, Z. Bazant. Inelastic Analysis of Structures. London: J. Wiley \& Sons, 2002.

[21] B. Jones, A. Thomas, Y. Hsu, M. Hilar. Evaluation of innovative sprayed-concrete-lined tunnelling. Geotechnical Engineering 161(GE3):137-149, 2008. DOI:10.1680/geng.2008.161.3.137.

[22] B.Jeremic, S. Sture. Implicit integrations in elasto-plastic geotechnics. International Journal for Mechanics of Cohesive-Frictional Materials and Structures 2:165-183, 1997. DOI:10.1002/(SICI)10991484(199704)2:2<165::AID-CFM31>3.0.CO;2-3.

[23] J. Vesely. The Use of Advanced Material Model for Numerical Modelling of Underground Structures in Clay. Ph.D. thesis, Czech Technical University in Prague, 2017.

[24] P. Mayne, F. Kulhawy. Soil mechanics and plastic analysis or limit design. Journal of Geotechnical Engineering, ASCE 108(GT6):851-872, 1986.

[25] J. Rott. Homogenisation and modification of composite steel-concrete lining, with the modulus of elasticity of sprayed concrete growing with time. Tunel 23(3):53-60, 2014.

[26] A. Thomas. Sprayed concrete lined tunnels: An introduction. Taylor \& Francis, 2009.

[27] J.Rott, D. Masin, J.Bohac, et al. Evaluation of k0 in stiff clay by back-analysis of convergence measurements from unsupported cylindrical cavity. Acta Geotechnica 10:719-733, 2015. DOI:10.1007/s11440-015-0395-7. 